\title{
Pengaruh Kualitas Layanan dan Lokasi \\ Terhadap Kepuasan dan Loyalitas Pelanggan pada Don's Warnet Cikarang
}

Asep Dony Suhendra

Akademi Sekretari dan Manajemen Bina Sarana Informatika Jakarta

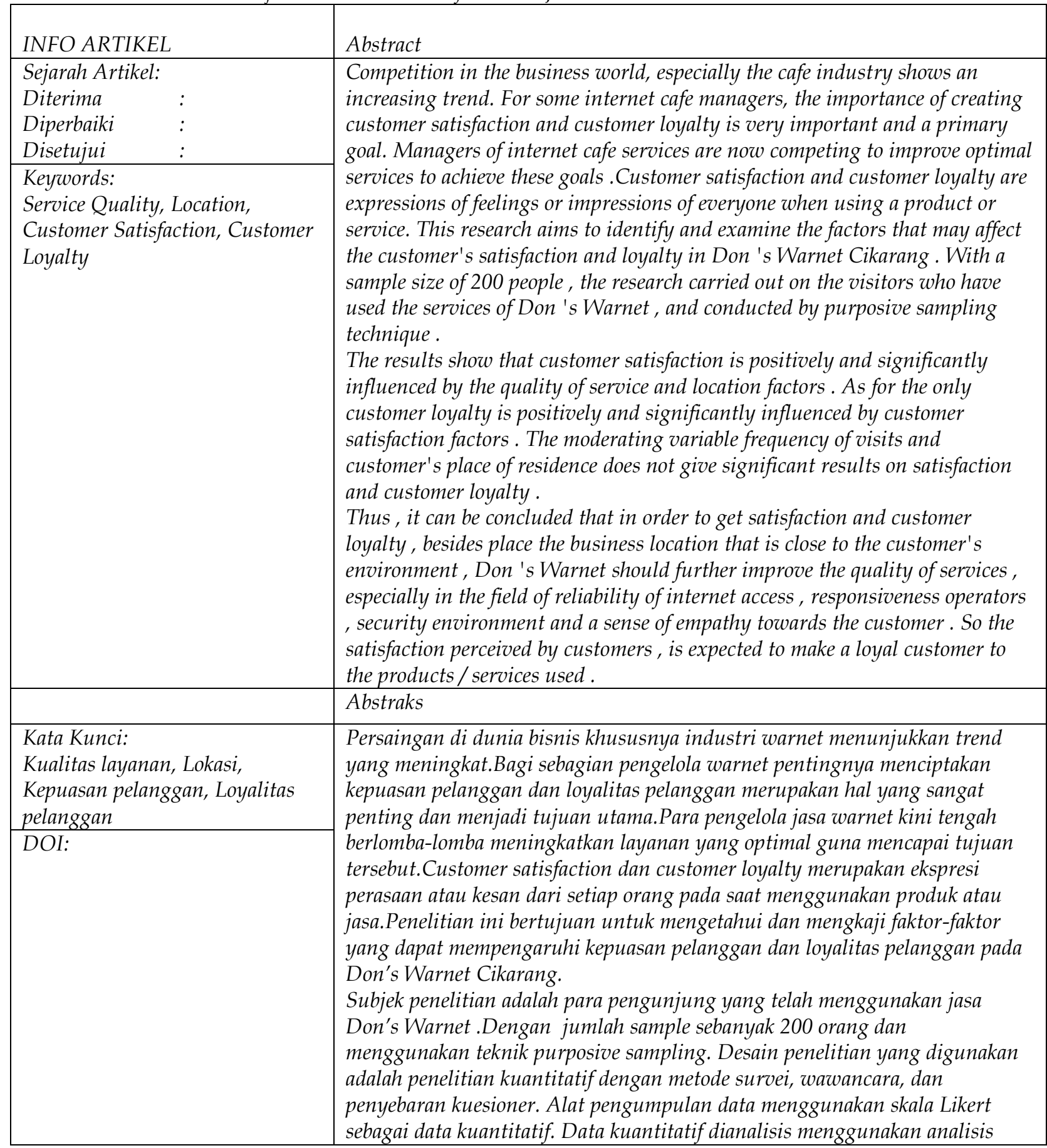


Pengaruh Kualitas Layanan dan LokasiTerhadap Kepuasan dan,..... Asep Dony Suhendra

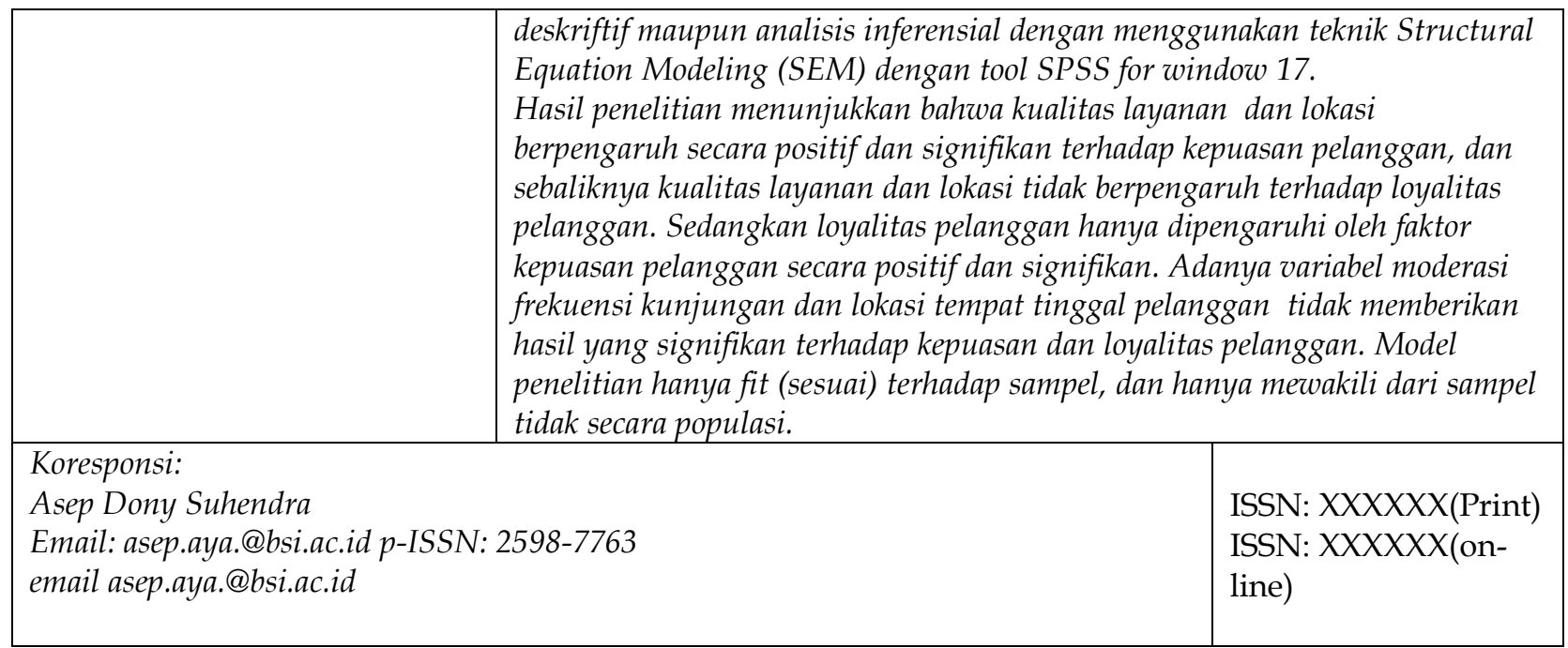

\section{PENDAHULUAN}

Kemajuan teknologi informasi terutama internet mendorong lahirnya industri baru. Banyak pihak yang melihat fenomena ini adalah langkah yang tepat dalam melakukan usaha bisnis.seperti jasa penyedia layanan internet atau lebih dikenal dengan Internet Service Provider (ISP), ecommerce, perusahaan online dan webhosting serta warung internet (warnet). Warnet merupakan salah satu peluang bisnis disektor jasa dengan pasar potensial yang terus berkembang. Menurut survei Asosiasi Penyelenggara Jasa Internet Indonesia (APJII), pengguna internet di indonesia pada tahun 2012 sebanyak 63 juta orang dan mengalami peningkatan pada tahun 2013 menjadi 82 juta orang.

Don's Warnet Cikarang adalah salah satu penyedia layanan internet yang terhitung baru, tapi cukup diperhitungkan.Berdiri sejak tahun 2010, Dengan mengutamakan kepuasaan konsumen. Don's Warnet memiliki fasilitas berupa Lokasi yang strategis, dengan 10 komputer LCD Monitor baru, ruangan bersih dan berpendingin, kecepatan koneksi yang stabil, dan berbagai fasilitas pendukung lainnya.Juga tersedianya berbagai makanan dan minuman ringn sehingga mampu menarik minat para pengunjung warnet. Hal tersebut telah menjadi keunggulan bersaing tersendiri bagi Dons Warnet dibanding warnet lainnya.

Seiring dengan berjalannya waktu, penyedia jasa internet semakin banyak bermunculan, Hal ini membuat Don's Warnet membutuhkan strategi bisnis yang lebih inovatif dan efektif agar dapat mengatasi tekanan pada persaingan tersebut, bahkan diharapkan dapat mengembangkan usahanya dengan lebih besar lagi.

Dengan kondisi persaingan yang sangat kompetitif, banyak perusahaan mempertahankan pasar mereka melalui program pengembangan loyalitas pelanggan. Ini merupakan salah satu strategi perusahaan untuk mempertahankan bisnis dan profit perusahaan (Arlan Ruly, 2006 dalam Partua Pramana, 2010:17).Imbalan dari loyalitas sendiri bersifat jangka panjang dan komulatif, jadi semakin lama seorang pelanggan loyal terhadap suatu produk/jasa, semakin besar laba yang diperoleh perusahaan dari seorang calon pelanggan (Griffin, 2003).

Dengan banyaknya pesaing, mempertahankan pelanggan bukanlah hal yang mudah. Sehingga selain dari pelayanan yang berkualitas, lokasi juga mempunyai peran penting dalam membangun loyalitas pelanggan.

Basu Swashta (2002) mengemukakan bahwa lokasi (place) menunjukkan berbagai kegiatan yang dilakukan perusahaan, untuk menjadikan produknya dapat diperoleh dan tersedia bagi konsumen.

Saat ini para penyedia layanan internet saling bersaing merebut hati para pelanggan. Sehingga dalam konteks Don's warnet Cikarang, kegagalan mempertahankan pelanggan menunjukkan suatu permasalahan yang cukup serius.

Mengacu pada permasalahan di atas, tujuan yang ingin dicapai dalam penelitian ini adalah:

1. Untuk mengetahui pengaruh kualitas layanan terhadap kepuasan pelanggan pada Don's warnet Cikarang.

2. Untuk mengetahui pengaruh kualitas 
Jurnal Studi Manajemen dan Bisnis

Vol. 5 (1) 2018: 1-11

layanan terhadap loyalitas pelanggan pada Don's warnet Cikarang.

3. Untuk mengetahui pengaruh lokasi terhadap kepuasan pelanggan pada Don's warnet Cikarang.

4. Untuk mengetahui pengaruh lokasi terhadap loyalitas pelanggan pada Don's warnet Cikarang.

5. Untuk mengetahui pengaruh kepuasan

\section{METODE}

Metode penelitian yang dipergunakan adalah metode survey, sedangkan desain penelitiannya adalah penelitian kausal, yakni hendak mengetahui hubungan sebab akibat antar variable (Sugiyono, 2009). Penelitian dilakukan dengan objek para pengunjung yang menggunakan jasa Don's Warnet Cikarang.

Data primer diperoleh dengan cara menyebarkan kuesioner kepada 200 responden yang dipilih secara purpose sampling. Data yang diperoleh dianalisis menggunakan analisis SPSS (Statistical Package for the Social Sciens) dengan mengkombinasikan aspek-aspek multiple regression (regresi berganda). Skala pengukuran yang digunakan terhadap pernyataan-pernyataan adalah Likert scale dengan skala pengukuran 1-4 untuk mendapatkan data yang bersifat interval.

Kerangka Pemikiran

Berdasarkan penjelasan secara teoritis maka dapat dikembangkan suatu pola hubungan yang menggambarkan pengaruh antara masing-masing variabel dalam bentuk kerangka pemikiran sebagai berikut :

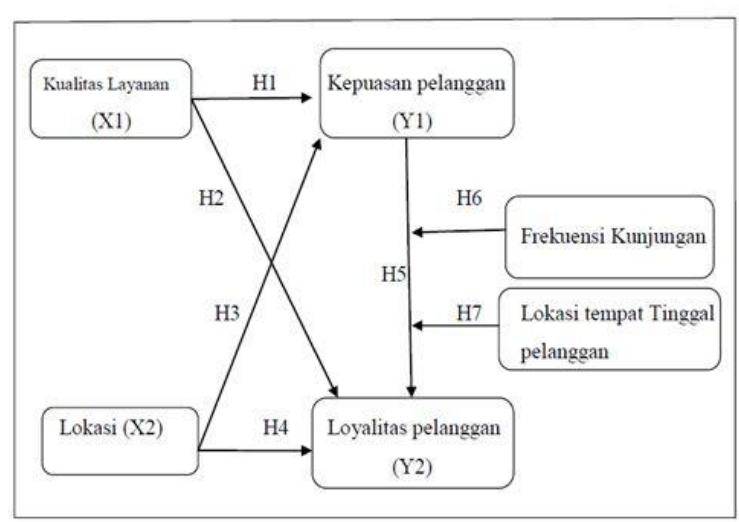

Sumber: Diolah untuk kepentingan penelitian pelanggan terhadap loyalitas pelanggan pada Don's warnet Cikarang.

6. Untuk mengetahui pengaruh keragaman frekuensi kunjungan terhadap kepuasan dan loyalitas pelanggan pada Don's warnet Cikarang.

7. Untuk mengetahui pengaruh keragaman lokasi tempat tinggal pelanggan terhadap kepuasan dan loyalitas pelanggan pada Don's warnet Cikarang.

\section{HASIL DAN PEMBAHASAN}

Uji Validitas dan Reliabilitas

Uji validitas dilakukan dengan membandingkan nilai $r$ hitung (untuk setiap butir dapat dilihat pada kolom corrected item-total correlations) dengan $r$ tabel untuk degree of freedom $(\mathrm{df})=\mathrm{n}-\mathrm{k}$, dalam hal ini $\mathrm{n}$ adalah jumlah sampel dan $\mathrm{k}$ adalah jumlah item. Jika $r$ hitung $>\mathrm{r}$ tabel, maka pertanyaan tersebut dikatakan valid (Ghozali, 2005: 45 ).

Alat untuk mengukur validitas adalah Korelasi Product Moment dari Pearson. Jadi Apabila $\mathrm{n}=$ 200 dan $\alpha=0,05$ maka $r$ tabel $=0,138$ dengan ketentuan:

Hasil $\mathrm{r}$ hitung $>\mathrm{r}$ table $(0,138)=$ Valid

Hasil $r$ hitung $<r$ table $(0,138)=$ Tidak valid

Sedangkan Rumus reliabilitas dalam penelitian ini menggunakan rumus koefisienAlpha Cronbach diukur berdasarkan skala Alpha Cronbach 0 sampai 1. Jika skalaitu dikelompok ke dalam lima kelas dengan range yang sama, maka ukurankemantapan alpha dapat diinterprestasikan sebagai berikut :

1. Nilai Alpha Cronbach 0,00 s.d. 0,20, berarti kurang reliable.

2. Nilai Alpha Cronbach 0,21 s.d. 0,40, berarti agak reliable.

3. Nilai Alpha Cronbach 0,42 s.d. 0,60, berarti cukup reliablel

4. Nilai Alpha Cronbach 0,61 s.d. 0,80, berarti reliable.

5. Nilai Alpha Cronbach 0,81 s.d. 1,00, berarti sangat reliable.

Analisis Statistik Deskriptif

Statistik deskriptif adalah statistik yang berfungsi untuk mendeskripsikan atau memberi gambaran terhadap obyek yang diteliti melalui data sampel atau populasi sebagaimana adanya, tanpa melakukan analisis dan membuat kesimpulan yang berlaku untuk umum.

Tabel .1 
Pengaruh Kualitas Layanan dan LokasiTerhadap Kepuasan dan,.....

Asep Dony Suhendra

Statistik Deskriptif dari Variabel penelitian:

Kualitas Layanan (KL), Lokasi (L), Kepuasan

Pelanggan (KP),

Loyalitas Pelanggan (LP), Moderasi Frekuensi

Kunjungan (Mod1) Lokasi Tempat Tinggal

Pelanggan(Mod2)

\begin{tabular}{|c|c|c|c|c|c|c|}
\hline & KL & $\mathbf{L}$ & KP & LP & MOD1 & MOD2 \\
\hline Valid & 200 & 200 & 200 & 200 & 200 & 200 \\
\hline Missing & 0 & 0 & 0 & 0 & 0 & 0 \\
\hline Mean & 46.88162 & 15.78290 & 16.18220 & 9.68834 & .59000 & .49000 \\
\hline Median & 45.56600 & 15.23300 & 15.21800 & 9.07200 & 1.00000 & .00000 \\
\hline Mode & 45.566 & 15.233 & 15.218 & 9.072 & 1.000 & .000 \\
\hline Std. Deviation & 9.404502 & 3.104225 & 3.558189 & 2.149183 & .493068 & .501154 \\
\hline Variance & 88.445 & 9.636 & 12.661 & 4.619 & .243 & .251 \\
\hline Skewness & .115 & .364 & -.320 & .063 & -.369 & .040 \\
\hline Kurtosis & .752 & .584 & 1.349 & .115 & -1.883 & -2.019 \\
\hline Range & 49.736 & 16.408 & 17.882 & 10.324 & 1.000 & 1.000 \\
\hline Minimum & 17.890 & 6.272 & 5.000 & 3.000 & .000 & .000 \\
\hline Maximum & 67.626 & 22.680 & 22.882 & 13.324 & 1.000 & 1.000 \\
\hline
\end{tabular}

Uji Multikolinieritas

Tabel.2

Coefficients $^{a}$

\begin{tabular}{|ll|r|c|}
\hline & & \multicolumn{2}{|c|}{ Collinearity Statistics } \\
\cline { 3 - 4 } Model & & Tolerance & \multicolumn{1}{c|}{ VIF } \\
\hline 1 & (Constant) & & \\
& $\mathrm{KL}$ & .537 & 1.864 \\
$\mathrm{~L}$ & .537 & 1.864 \\
\hline
\end{tabular}

a. Dependent Variable: KP

Dalam sebuah penelitian untuk mendeteksi ada atau tidaknya multikolinearitas didalam model regresi adalah dengan melihat dari nilai Variance Inflation Factor (VIF), dan nilai tolerance.Apabila nilai tolerance lebih besar dari 0.1 serta nilai VIF lebih kecil dari 10, maka dapat disimpulkan tidak terjadi multikolinearitas antara variabel bebas dalam model regresi.

Terlihat pada table diatas nilai tolerance adalah 0.537 dan nilai variance inflation factor ( VIF ) adalah 1.864 maka dapat disimpulkan tidak terjadi multikolinearitas antara variable bebas

Uji Heteroskedastisitas gambar.2

Scatterplot )

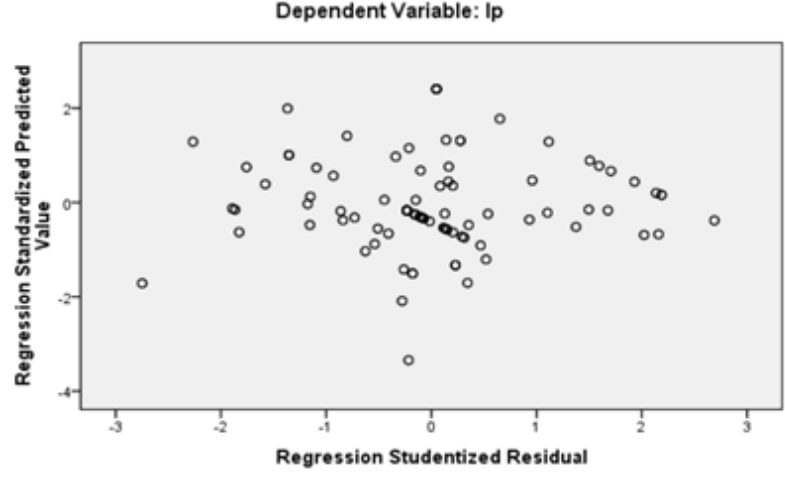

Hasil uji Keteroskedastisitas Pada gambar scatterplot diatas terdapat titik-titik membentuk pola tertentu yang teratur seperti bergelombang, melebar, kemudian menyempit maka dapat disimpulkan telah terjadi heteroskedastisitas. Yang berarti bahwa dalam model regresi telah terjadi ketidaksamaan varian dari satu residual pengamatan ke pengamatan yang lain.

Uji Normalisasi Data ( Kolmogorov - Smirnov

Uji Kolmogorov-Smirnov termasuk dalam uji nonparametrik untuk kasus satu sampel.Uji ini digunakan untuk menguji asumsi normalitas data.Tes dalam uji ini adalah tes goodness of fit yang mana tes tersebut untuk mengukur tingkat kesesuian antara distribusi serangkaian sampel (data observasi) dengan distribusi teoritis tertentu.

Penerapan pada uji Kolmogorov Smirnov adalah bahwa jika signifikansi di bawah 0,05 berarti data yang akan diuji mempunyai perbedaan yang signifikan dengan data normal baku, berarti data tersebut tidak normal.

Sedangkan jika signifikansi di atas 0,05 maka berarti data yang akan diuji tidak mempunyai perbedaan yang signifikan dengan data normal baku, berarti data tersebut normal.

Dari hasil analisis Kolmogrov smirnov pada semua variabel penelitian ini memiliki nilai signifikasi diatas 0.05 , berarti data tersebut berdidtribusi normal.

AnalisisRegresiLinear Berganda KepuasanPelanggan

Model regresi linear berganda Kepuasan

Pelanggan yang diajukan :

$\hat{\mathrm{Y}} 1=\mathrm{a}+\mathrm{b} 1 \mathrm{X} 1+\mathrm{b} 2 \mathrm{X} 2+\mathrm{e}$

Dimana :

$\hat{Y} 1=$ Kepuasan pelanggan

$\mathrm{a}=$ konstanta

b1= Koefisien regresi variabel X1 ( kualitaslayanan) 
Jurnal Studi Manajemen dan Bisnis

Vol. 5 (1) 2018: 1-11

b2 = Koefisien regresi variabel X2 (lokasi)

X1 $=$ Kualitas Layanan

$\mathrm{X} 2=$ Lokasi

$\mathrm{e}=$ error $/$ variabel pengganggu

Tabel.3

Anova Regresi Terinci :

(L)

Pengaruh Kualitas Layanan (KL) dan Lokasi

terhadap Kepuasan Pelanggan (KP)

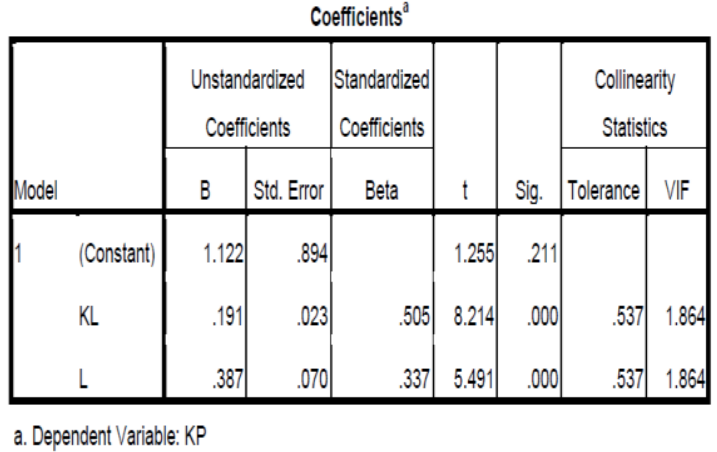

Untuk variabel kualitas layanan dan lokasi, diperoleh hasil bahwa Sig. $<0.05$. Sehubungan dengan itu, maka Ho ditolak dan Ha diterima. Hal ini mengindikasikan bahwa ternyata kedua variable tersebut secara parsial mempunyai pengaruh signifikan terhadap kepuasan pelanggan.

Analisis Regresi Linear Berganda Loyalitas Pelanggan

Model regresi ganda linear Loyalitas Pelanggan yang diajukan :

$\hat{Y} 2=a+b 1 X 1+b 2 X 2+b 3 Y 1+e$

\section{Dimana :}

$\hat{Y} 2=\quad$ Loyalitas pelanggan

$\mathrm{a}=\quad$ konstanta

$\mathrm{b} 1=\quad$ Koefisien regresi variabel X1 (kualitas

layanan)

b2 $=\quad$ Koefisien regresi variabel X2 (lokasi)

b3 $=\quad$ koefisien regresi variabel Y1 (Kepuasan

pelanggan)

$\mathrm{X} 1=\quad$ Kualitas Layanan

$\mathrm{X} 2=\quad$ Lokasi

$\mathrm{Y} 1=\quad$ Kepuasan pelanggan

$\mathrm{e}=$ error $/$ variabel pengganggu

Tabel.4

Anova Regresi Terinci :

Pengaruh Kualitas Layanan (KL), Lokasi (L)

dan kepuasan Pelanggan (KP)

terhadap Loyalitas Pelanggan (LP)

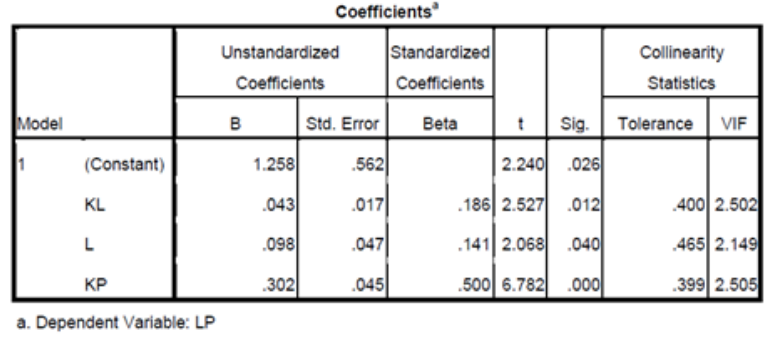

Berdasarkan data uji regresi Untuk variabel loyalitas pelanggan, ternyata hanya di pengaruhi oleh kepuasan pelanggan saja dengan hasil Sig. < 0.05 . Sehubungan dengan itu, maka Ho ditolak dan Ha diterima. Hal ini menjelaskan bahwa kepuasan pelanggan secara parsial mempunyai pengaruh signifikan terhadap loyalitas pelanggan. Sedangkan kualitas layanan dan lokasi tidak mempengaruhi secara signifikan terhadap loyalitas pelanggan.

Analisis Regresi Linear Berganda Kepuasan Pelanggan

Dengan Variabel Moderating

Model regresi linear berganda Kepuasan Pelanggan dengan variabel moderating jenis frekuensi kunjungan dan lokasi tempat tinggal yang diajukan dalam penelitian ini :

$\hat{Y} 1=a+b 1 X 1+b 2 X 2+b 3 \operatorname{Mod} 1+b 4 \operatorname{Mod} 2+e$

Dimana :

$\hat{Y} 1=$ Kepuasan pelanggan

$\mathrm{a}=\quad$ konstanta

b1 $=\quad$ Koefisien regresi variabel X1 (kualitas

layanan)

b2 $=\quad$ Koefisien regresi variabel X2 (lokasi)

b3 $=\quad$ Koefisien regresi variabel moderating 1 (

Frekeunsi Kunjungan)

b4 $=\quad$ Koefisien regresi variabel moderating 2 (

lokasi tempat tinggal)

$\mathrm{X} 1=$ Kualitas Layanan

$\mathrm{X} 2=\quad$ Lokasi

Mod1 $=$ Frekuensi Kunjungan

$\operatorname{Mod} 2=$ Lokasi tempat tinggal

$\mathrm{e}=$ error $/$ variabel pengganggu

Tabel.5 
Pengaruh Kualitas Layanan dan LokasiTerhadap Kepuasan dan,..... Asep Dony Suhendra

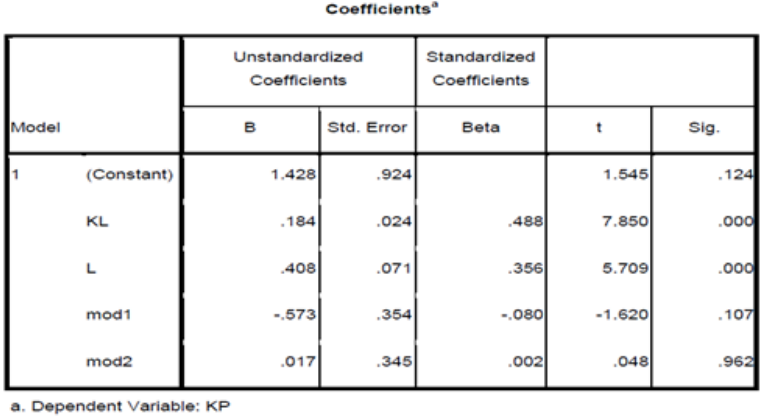

Untuk variabel kualitas layanan dan lokasi diperoleh hasil bahwa Sig. $<0.05$. Sehubungan dengan itu, maka Ho ditolak dan Ha diterima. Hal ini mengindikasikan bahwa ternyata kualitas layanan dan lokasi secara parsial mempunyai pengaruh signifikan terhadap kepuasan pelanggan. Sedangkan untuk variable frekuensi kunjungan dan lokasi tempat tinggal pelanggan, secara parsial tidak mempunyai pengaruh signifikan terhadap kepuasan pelanggan.

Analisis Regresi Linear Berganda Loyalitas Pelanggan

Dengan Variabel Moderating

Model regresi linear berganda Loyalitas Pelanggan dengan variabel moderating jenis frekeunsi

kunjungan dan lokasi tempat tinggal yang diajukan dalam penelitian ini :

$\hat{\mathrm{Y}} 2=\mathrm{a}+\mathrm{b} 1 \mathrm{X} 1+\mathrm{b} 2 \mathrm{X} 2+\mathrm{b} 3 \mathrm{Y} 1+\mathrm{b} 4 \operatorname{Mod} 1+\mathrm{b} 5 \operatorname{Mod} 2+\mathrm{e}$

Dimana :

$\hat{\mathrm{Y}} 2=$ Loyalitas pelanggan

$\mathrm{a}=$ konstanta

$\mathrm{b} 1=\quad$ Koefisien regresi variabel X1 (kualitas

layanan)

$\mathrm{b} 2=\quad$ Koefisien regresi variabel X2 (lokasi)

b3 $=\quad$ Koefisien regresi variabel $Y 1$ (kepuasan

Pelanggan)

$\mathrm{b} 4=\quad$ Koefisien regresi variabel moderating 1

(frekuensi kunjungan)

b5 $=\quad$ Koefisien regresi variabel moderating 2

(Lokasi tempat tinggal)

$\mathrm{X} 1=$ Kualitas Layanan

$\mathrm{X} 2=$ Lokasi

$\mathrm{Y} 1=$ kepuasan Pelanggan

Mod1 $=$ Frekuensi Kunjungan

Mod2 $=$ Lokasi tempat tinggal

$\mathrm{e}=$ error $/$ variabel pengganggu

Tabel.6

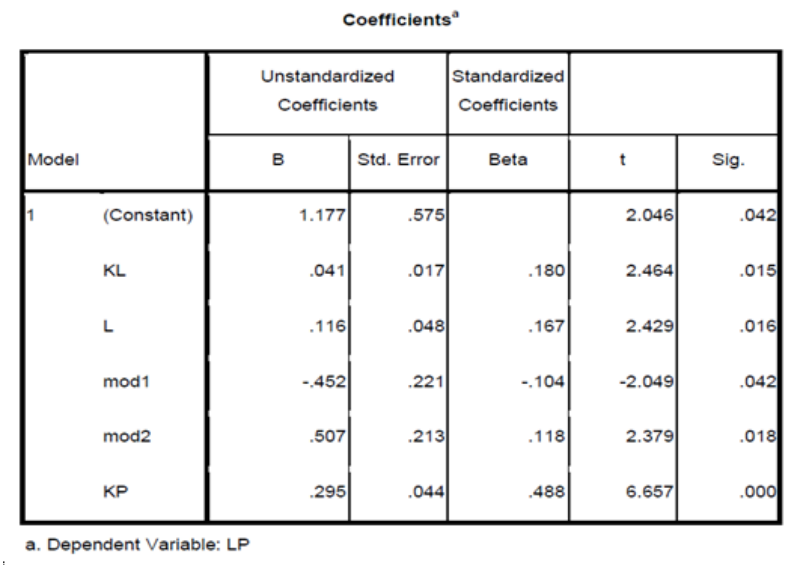

Hasil uji regresi pada variabel loyalitas pelanggan, diketahui bahwa hanya variabel kepuasan pelanggan yang memperoleh nilai Sig. $<0.05$. Sehubungan dengan itu, maka Ho ditolak dan Ha diterima. Hal ini mengindikasikan bahwa ternyata hanya kepuasan pelanggan saja yang secara parsial mempunyai pengaruh signifikan terhadap loyalitas pelanggan. Sedangkan kualitas layanan, lokasi, frekunesi kunjungan dan lokasi tempat tinggal pelanggan secara parsial tidak mempunyai pengaruh signifikan terhadap loyalitas pelanggan.

\section{SIMPULAN DAN SARAN}

Kesimpulan

Berdasarkan analisis data yang telah dilakukan dalam penelitian ini, maka dapat ditarik kesimpulan sebagai berikut :

a. Penelitian membuktikan bahwa kepuasan pelanggan dapat dipengaruhi secara signifikan oleh faktor kualitas layanan. sehingga disimpulkan bahwa apabila perusahaan Don's warnet telah meningkatkan kualitas layanan terutama dalam bidang kehandalan akses internet, daya tanggap operator, jaminan keamanan lingkungan serta rasa empathy terhadap pelanggan, Maka kepuasan pelanggan telah tercapai. Sehingga diharapkan dengan kepuasan yang diterima, pelanggan dapat menjadi loyal terhadap produk/jasa yang digunakan.

b. Kepuasan pelanggan juga dipengaruhi oleh faktor lokasi perusahaan. Sehingga dapat disimpulkan bahwa apabila perusahaan menempati lokasi usaha yang strategis dengan akses yang mudah dijangkau oleh transportasi umum, maka hal ini dapat memberikan kepuasan pada pelanggan. Sehingga diharapkan pelanggan bisa dengan mudah untuk datang kembali dalam menggunakan produk/jasa perusahaan. 
c. Loyalitas pelanggan dipengaruhi secara signifikan oleh faktor kepuasan pelanggan. Sehingga dapat disimpulkan apabila perusahaan menambah satu tingkat kepuasan pelanggan, maka perilaku pelanggan akan naik satu tingkat untuk menjadi loyal terhadap produk/jasa yang digunakan. Begitu juga sebaliknya, apabila perusahaan menurunkan satu tingkat kepuasan pelanggan, maka loyalitas pelanggan akan menurun sebanyak satu tingkat. Sehingga diharapkan agar perusahaan terus meningkatkan kepuasan terhadap para pelanggan, agar tingkat loyalitas pelanggan terhadap produk/jasa yang digunakan semakin tinggi.

Saran

a. Memperhatikan fakta di lapangan, sebaiknya Don's Warnet segera mengembangkan manajemen bisnisnya dengan basis hubungan pelanggan CRM (customer relationship management). Peningkatan kadar keintiman hubungan dua arah antara perusahaan dan pelanggan, diharapkan akan menciptakan benefit yang tidak hanya dinikmati oleh perusahaan tetapi juga oleh pelanggannya.

b. Sebaiknya Don's Warnet segera mengembangkan data base pelanggannya. Banyak manfaat yang diperoleh dari kehadiran data base tersebut, yakni :

1. untuk menilai life time value atau net present value dari profit yang dihasilkan oleh rata-rata pelanggan dalam waktu tertentu.

2. untuk segmentasi pelanggan yang ada dalam database tersebut, salah satunya berdasarkan recency, frequency, dan monetary value

3. untuk menyesuaikan program pemasaran sesuai dengan kebutuhan pelanggan, agar marketing mix (bauran pemasaran) yang menyangkut kebijakan harga, promosi, distribusi, atau produk yang dijalankan sesuai sasaran.

4. untuk melakukan profiling pelanggan dan pendalaman terhadap life style pelanggan.

\section{DAFTAR PUSTAKA}

Andreassen,W, Lindestad.B, 2008, Customer Ardhana, Oldy (2010). “Analisis PengaruhKualitas Pelayanan, Harga, dan Lokasi terhadap Kepuasan Pelanggan (Studi pada Bengkel Caesar Semarang)". Fakultas Ekonomi Universitas Diponegoro.

Chandrashekaran, Murali, Kristin Rotte, and Stephen S. Tax., (2006), " Satisfaction Strength and Customer Loyalty." Journal Of Marketing Research, 1-28

Griffin, Jill, (2003), Customer Loyalty; Menumbuhkan dan Mempertahankan Kesetiaan Pelanggan. Edisi Revisi, Terjemahan Dwi Kartini Yahya, Jakarta: Erlangga.

Hasan, Ali, (2008),Marketing. Media Pressindo: Yogyakarta

Lupiyoadi, Rambat. (2001). Manajemen

Pemasaran Jasa Teori dan Praktik, Jakarta: Penerbit Salemba Empat.

Partua pramana, (2010). Analisis Pengaruh Kualitas layanan, kepuasan pelanggan dan Lokasi terhadap loyalitas pelanggan.(study kasus pada warnet Chamber).Skripsi. Fakultas Ekonomi Universitas Diponegoro.Semarang

Perangin Angin, Jasanta, (2009), “Studi

Peningkatan Loyalitas Pelanggan Ritel (Studi Kasus Toko Amelina)". Tesis. Megister Manajemen.

Universitas Diponegoro Semarang

Swasta, Basu. 2001. Azas-azas Marketing. Yogyakarta : Liberty.

Sugiyono. 2009. Metode Penelitian Kuantitatif, Kualitatif dan R\&D. Bandung : Alfabeta

Tjiptono, Fandy, (2005), Service, Quality dan Satisfaction. Yogyakarta: Penerbit Andi 